\title{
Title: Overweight and obesity in childhood and adolescence: findings from the UK Millennium Cohort Study, up to age 14
}

Running title: overweight and obesity in early life

Authors: Dr Benedetta Pongiglione ${ }^{1,2^{*}}$, Prof Emla Fitzsimons ${ }^{2,3}$

Keywords: Obesity; Overweight; Adolescence; Millennium Cohort Study

${ }^{1}$ Center for Research on Health and Social Care Management, Bocconi University, Milan;

${ }^{2}$ UCL Institute of Education, London

${ }^{3}$ UCL Institute of Education and Institute for Fiscal Studies, London;

* Author to whom correspondence and offprint requests are to be sent: Name: Benedetta Pongiglione Postal address: Via Roentgen 1, 20136 Milano, Italy Tel: +390258362504

e-mail address: benedetta.pongiglione@unibocconi.it

Conflict of Interest statement

The authors declare no conflict of interest. 


\title{
Overweight and obesity in childhood and adolescence:
}

\author{
Findings from the UK Millennium Cohort Study, up to age 14
}

\begin{abstract}
Background: The aims of this work are threefold: (1) Show the pathway of overweight and obesity, for current generation of adolescents, since early childhood in the UK. (2) Identify factors associated with the risk of overweight/obesity at age 14. (3) Study transitions into and out of overweight/obesity, from early adolescence to mid-adolescence.

Methods: A sample of 10825 children in the UK Millennium Cohort Study was selected for analysis. BMI was calculated using measured height and weight available at every sweep since age 3 , and overweight and obesity were defined using the IOTF classification. Possible factors associated with the risk of excess weight include sociodemographic characteristics, early life circumstances, and behavioral and lifestyle factors in adolescence.

Results: $19 \%$ of the sample of 14 -year olds in $2015 / 16$ is classified as overweight ( $95 \% \mathrm{Cl}$ 18.4-20.0), and $7.5 \%$ as obese $(95 \% \mathrm{Cl} 7.0-7.9)$, with proportions very similar across sexes. Protective factors for excess weight include high maternal education, breastfeeding, home ownership and child's active behavior. The likelihood of transiting out of excess weight/obesity between 11 and 14 is higher than likelihood of transiting in. Predictors of transiting out of excess weight/obesity include child's active behavior and puberty onset.

Conclusions: This study provides new evidence that the profile of rising trends in excess weight observed during childhood had stabilized by mid-adolescence. However, rates of excess weight remain high, overweight and obesity in childhood and adolescence remain of major public health concern. The study identifies some risk and protective factors to reinforce the Government commitment to reducing excess weight in childhood.
\end{abstract}




\section{Introduction}

Childhood overweight and obesity are of major concern in the majority of industrialized nations, and the childhood obesity epidemic is growing globally, with large variations in secular trends across countries (Wang \& Lobstein, 2006). Globally, the prevalence of overweight and obesity combined has risen by $47.1 \%$ for children over the period 1980 to 2013 (compared to $27.5 \%$ for adults). Remarkable increases have been observed in developed countries over this period, with $23.8 \%$ of boys and $22.6 \%$ of girls being either overweight or obese in 2013 , compared to $16.9 \%$ and $16.2 \%$ respectively in 1980 . Sex differences in the levels of and trends in overweight and obesity are small ( $\mathrm{Ng}$ et al., 2014). A recent study of worldwide trends in Body Mass index (BMI) in children and adolescents finds that the rising trends in children's and adolescents' BMI have levelled off in many high-income countries, albeit at high levels, but have accelerated in parts of Asia (Abarca-Gómez et al., 2017).

In the UK, research on school-aged children, spanning 1974 to 1998 (Chinn \& Rona, 2001; Lobstein, James, \& Cole, 2003) found that in 1998 the prevalence of overweight boys and girls was $17 \%$ and $23.6 \%$ respectively. This represented an increase of $150 \%$ since 1974. In England, the period 1995 to 2005 witnessed a general increase in childhood obesity from around $12 \%$ to $18 \%$, which has since levelled off (Conolly \& Neave, 2016). The Health Survey for England found that among children aged 11 to 15, the prevalence of obesity has fluctuated between $16 \%$ and $20 \%$ during the period 2008 to 2015. Findings from the Millennium Cohort Study (MCS) show a stark increase in rates of obesity between ages 7 (2007/08) and 11 (2011/12), from 13\% to 20\% (Platt et al., 2014).

Children who are overweight or obese face an increased risk of many health problems, including asthma (Lang, 2012), cardiovascular disease (Bridger, 2009), type 2 diabetes (Pulgaron \& Delamater, 2014), cancer (Renehan, Tyson, Egger, Heller, \& Zwahlen, 2008) and chronic kidney disease (Asia Pacific Cohort Studies Collaboration, 2004; Emerging Risk Factors Collaboration, 2011). Childhood overweight and obesity is also associated with psychological problems such as low self-esteem and depression, and can have a major and enduring impact on an individual's life (Russell-Mayhew, McVey, Bardick, \& 
Ireland, 2012). Overweight/obesity in childhood is a strong predictor of overweight and obesity in adulthood (Guo, Wu, Chumlea, \& Roche, 2002). Younger generations are likely to accumulate greater exposure to overweight or obesity throughout their lives (2015), to the extent that cohorts born after the 1980s already have probabilities of overweight or obesity in childhood that are two to three times greater than for cohorts born before the 1980s (Johnson et al., 2015).

Overweight and obesity are complex and multifactorial conditions affected by several genetic, behavioral, environmental, socioeconomic factors (Güngör, 2014; Han, Lawlor, \& Kimm, 2010). A number of studies have investigated risk factors, including breastfeeding, whose association with overweight and obesity in late childhood and adolescence is inconsistent across studies (Gillman et al., 2001; Hediger, Overpeck, Kuczmarski, \& Ruan, 2001; Kramer et al., 2009), and maternal smoking during pregnancy, associated with increased risk of overweight and obesity (Toschke, Koletzko, Slikker, Hermann, \& von Kries, 2002; Von Kries, Toschke, Koletzko, \& Slikker Jr, 2002; Widerøe, Vik, Jacobsen, \& Bakketeig, 2003). A review of international studies found socio-economic status to be inversely associated with overweight/obesity (Shrewsbury \& Wardle, 2008); lifestyle behaviours, such as physical activity, sleep, diet, are also known correlates of overweight /obesity in adolescence, reducing the risk of having excess weight (Thibault, Contrand, Saubusse, Baine, \& Maurice-Tison, 2010; Vieno, Santinello, \& Martin, 2005; Wilkie, Standage, Gillison, Cumming, \& Katzmarzyk, 2016).

In this paper we use data from the UK Millennium Cohort Study (MCS) to examine objective measures on $\mathrm{BMI}$ and overweight/obesity status among adolescents aged 14 in 2015 , and analyze prevalence and trends across childhood (from age 3 ). The contributions of the paper are threefold. First, we show the profile of overweight and obesity in the UK, for today's generation of adolescents, since early childhood. Second, we identify factors that are associated with the risk of overweight and obesity at age 14, and third, we study transitions into and out of overweight/obese statuses, from early adolescence (age 11) to mid-adolescence (age 14), an important transitional stage when individuals increase significantly in their autonomy and independence (Wray-Lake, Crouter, \& McHale, 2010). The overarching aim is to inform policy by providing up to 
date evidence on the current risk of overweight and obesity of adolescents, alongside understanding the factors associated with changes in weight status over time.

\section{Methods}

\section{Participants}

The MCS is a large-scale longitudinal cohort study following the lives of children born in the UK in $2000-02.18,552$ families (18,818 children) were recruited to the cohort at baseline to be nationally representative (Connelly \& Platt, 2014; Joshi \& Fitzsimons, 2016). There have been six sweeps of data collection available for analysis to date, at ages 9 months and 3, 5, 7, 11 and 14 years. Since age 3, the MCS has collected objective measurements of study participants' height and weight, making it a unique, nationallyrepresentative resource for the study of childhood overweight and obesity. 11,726 families were interviewed at age 14 , corresponding to 11,872 children. In this study, we exclude twins and triplets $(\mathrm{N}=308)$. This is to avoid the issue of nonindependence of observations, and is justified by the very modest number of twins/triples in the sample (2.6\%). Individuals had their weight and height objectively measured by trained interviewers, following well-established protocols (Fitzsimons, 2017). 739 (6.4\%) of the 11,564 singleton respondents did not provide valid measure of BMI, therefore information on BMI is available for 10,825 singleton children. When considering transitions from age 11 to 14 , the sample comprises respondents taking parts in sweeps 5 and $6(\mathrm{~N}=10,123)$. Figure $A 1$ in the Supporting Information illustrates the process of sample selection at sweep 6.

To estimate prevalence of overweight and obesity in childhood and adolescence, we selected respondents with complete records on weight and height in the specific sweep - rather than respondents with complete records in all sweeps - in order to maximise sample size at each sweep.

Two types of survey weights are used - cross-sectional and longitudinal (Mostafa \& Ploubidis, 2017). Cross-sectional weights maximize the representativeness of each sweep as standalone study, whilst longitudinal weights adjust for non-response due to 
attrition. All descriptive statistics use cross-sectional weights (results presented in Tables 1, 2 and 3); longitudinal weights are used in the logit models for excess weight at age 14 and transition analyses (Tables 4 and 5 respectively). All analyses allow for the data being clustered by ward of initial residence. If individuals living in specific areas are more similar than individuals living elsewhere, the data will be correlated. This means a straightforward estimate of standard errors will be incorrect and the significance tests invalid. To ensure this does not occur, we use clustered robust standard errors in standard analysis, in agreement with MCS guidelines (Ketende \& Jones, 2011). Data for this analysis are publicly available and obtained from the UK Data Archive, University of Essex.

\section{Outcome variables: excess weight and obesity statuses}

$\mathrm{BMI}$ is the most frequently used measure for child obesity prevalence in the UK. Children are normally classified as overweight or obese by comparing their BMI with a reference population that describes the distribution of BMI within a population by age and sex. This is necessary because a child's BMI changes with age and sex so fixed thresholds, as applied to adults, cannot be used. The most widely used methods used in the UK are cut-offs based on the UK1990 growth reference and the international classification system commonly referred to as the International Obesity Task Force (IOTF) cut-offs. A short description of each is provided in the Supporting Information 1. In this paper, we use the IOTF system for classification. UK90-based prevalence of overweight and obesity were also estimated as a sensitivity analysis and are available upon request.

We consider overweight and obesity combined (referred to as "excess weight"), as well as obesity only. Underweight, as defined by Cole and colleagues (Cole, Flegal, Nicholls, \& Jackson, 2007), was combined with normal weight due to its very low prevalence in the categories of thinness and severe thinness (grades 2 and 3 respectively) at around $1.5 \%$ at age 14 (see Supporting Information Table A1).

\section{Predictors of excess weight and obesity at age 14}


The factors identified as possible risk factors of overweight and obesity include sociodemographic characteristics, early life circumstances and behaviours, and current behavioural and lifestyle factors. Previous studies have identified predictors of excess weight in childhood (see for example Apfelbacher et al., 2008; Massion et al., 2016) and adolescence (Inchley, Currie, Jewell, \& Breda, 2017). We draw on existing literature and select predictors also in accordance with the characteristics and objectives of this study. They include child sex, ethnicity and country of birth; early life information including on birth weight, breastfeeding for at least 90 days, maternal smoking during pregnancy, maternal alcohol consumption at child age 9 months; maternal education, distinguishing five levels of education in a multi-categorical variable; number of siblings, family structure at age 14 (whether single parent household or not), and home ownership at age 14. We also include the following lifestyle and behavioural factors of the study member at age 14: whether ever engaged in binge drinking; whether ever smoked; physical activity (days last week spent doing moderate to vigorous physical activity); sedentary behaviour/inactivity (TV watching); sleeping behaviour (weekday bedtime); and healthiness of diet, captured by four-item "Eating Choices Index" (ECI) which comprises four elements: (i) consumption of breakfast; (ii) consumption of fruit; (iii) type of milk consumed; and (iv) type of bread consumed, on a score ranging from 4 to 20, with a score of 20 indicating the healthiest diet (Pot, Richards, Prynne, \& Stephen, 2014). Finally, based on existing studies we included as a predictive factor an indicator of pubertal status (Li, Liu, Deng, Chen, \& Liu, 2017) consisting of menarche for females (Al-Awadhi et al., 2013; Bralic et al., 2012), and voice deepening for males (Tanner, 1962), reported by participants at age 14 .

\section{Statistical Analysis}

To describe the distribution of prevalence of overweight and obesity, significance of differences across classes are tested using chi-square tests.

To identify possible factors positively and negatively associated with the risk of overweight, multivariable logistic models are estimated using longitudinal weights to adjust for non-response. Models are run separately for the risk of excess weight and 
obesity. Additionally, we estimate multinomial logistic regression for a categorical outcome distinguishing normal weight (reference category), overweight and obesity, reporting results as relative risk ratios (RRR).

Changes in normal weight, overweight or obesity status are studied distinguishing changes from late childhood (age 11) to adolescence (age 14). This is to understand pathways out of and into overweight between these important lifecycle stages. We chose this transition as particularly policy relevant, representing the move from primary to secondary school, and an important shift in autonomy and decision making, with young people taking on more of their own decisions around health, nutrition, and exercise. We first create transition matrices separately for normal weight and overweight/obesity status between age 11 and 14, from the period of late childhood to adolescence. We next estimate logistic models to examine predictors of the likelihood of transiting out of excess weight (model 1) and obesity (model 2), conditional respectively on being excess weight and obese at age 11 .

All analyses were conducted using STATA statistical software, version 14 SE.

\section{Results}

Trends in prevalence of overweight and obesity with 95 confidence intervals are presented by sex, from age 3 to 14 years in Table 1. Both overweight and obesity increase as respondents grow up, with proportions slightly higher among females compared to males, but no major sex differences. A stark increase in overweight is observed between ages 7 and 11 , with proportions rising from $15 \%$ to $21 \%$ in girls and from $12 \%$ to $18 \%$ in boys. Between ages 11 and 14, the prevalence of overweight and obesity is substantially stable, with $20 \%$ and $18 \%$ of female and male respondents classified as overweight and $8 \%$ and $7.8 \%$, respectively, as obese. This equates to $28 \%$ of females and $26 \%$ of males being of excess weight status at age 14 . Hence, from age 11 we observe a slight decline in overweight among females and a slight increase in obesity for both sexes.

The lower part of Table 1 presents proportions of overweight and obesity from age 3 to 14 by country, with $95 \%$ confidence intervals. Trajectories are similar across countries, especially for overweight. At almost every age, Northern Ireland has the highest prevalence of both overweight and obesity, closely followed by Wales, while Scotland 
and England present the lowest prevalence of overweight and obesity at each age. At age 14, proportions of overweight status range from $19 \%$ in England $(95 \% \mathrm{Cl} 18.0 ; 19.9$ ) to $21 \%$ in Northern Ireland $(95 \% \mathrm{Cl} 18.7-23.6)$ and proportions of obese status range from $7.1 \%$ in Scotland $(95 \% \mathrm{Cl} 5.6-8.6)$ to $9.3 \%$ in Wales (95\% Cl 7.8-10.7). Country differences in overweight and obesity are significantly different from each other at the 10\% level (Based on chi-square tests. For overweight $p$-value $=0.078$, for obesity $p$ value $=0.086)$.

Table 1. Overweight and obesity, by age, sex and country

\begin{tabular}{|c|c|c|c|c|c|c|c|}
\hline & & & Age 3 & Age 5 & Age 7 & Age 11 & Age 14 \\
\hline \multirow{8}{*}{ Sex } & \multirow{4}{*}{ Females } & Over- & 12.96 & 16.62 & 15.31 & 21.43 & 20.4 \\
\hline & & weight & $(11.99 ; 13.93)$ & $(15.56 ; 17.68)$ & $(14.3 ; 16.32)$ & $(20.29 ; 22.56)$ & $(19.32 ; 21.48)$ \\
\hline & & & 4.47 & 5.74 & 6.55 & 6.65 & 8.22 \\
\hline & & estly & $(3.99 ; 4.96)$ & $(5.17 ; 6.31)$ & $(5.95 ; 7.14)$ & $(6.03 ; 7.26)$ & $(7.48 ; 8.95)$ \\
\hline & \multirow{4}{*}{ Males } & Over- & 12.38 & 12.92 & 12.03 & 18.29 & 18.03 \\
\hline & & weight & $(11.44 ; 13.32)$ & $(11.97 ; 13.86)$ & $(11.13 ; 12.93)$ & $(17.23 ; 19.35)$ & $(17.02 ; 19.05)$ \\
\hline & & \multirow{2}{*}{ Obesity } & 4.31 & 4.9 & 4.89 & 6.28 & 7.82 \\
\hline & & & $(3.84 ; 4.78)$ & $(4.38 ; 5.43)$ & $(4.38 ; 5.41)$ & $(5.68 ; 6.87)$ & $(7.11 ; 8.53)$ \\
\hline \multirow{16}{*}{ Country } & \multirow{4}{*}{ England } & Over- & 13.09 & 15 & 14.21 & 20.96 & 18.95 \\
\hline & & weight & $(12.4 ; 13.78)$ & $(14.23 ; 15.77)$ & $(13.47 ; 14.95)$ & $(20.08 ; 21.84)$ & $(18.04 ; 19.86)$ \\
\hline & & h & 4.29 & 5.25 & 5.7 & 6.36 & 8.01 \\
\hline & & שn & $(3.87 ; 4.7)$ & $(4.77 ; 5.73)$ & $(5.21 ; 6.19)$ & $(5.84 ; 6.89)$ & $(7.38 ; 8.64)$ \\
\hline & \multirow{4}{*}{ Scotland } & Over- & 13.84 & 14.73 & 15.1 & 20.22 & 19.38 \\
\hline & & weight & $(12.17 ; 15.51)$ & $(12.94 ; 16.52)$ & $(13.32 ; 16.88)$ & $(18.12 ; 22.31)$ & $(17.1 ; 21.65)$ \\
\hline & & & 5.13 & 5.39 & 4.36 & 5.21 & 7.07 \\
\hline & & (N & $(4.06 ; 6.19)$ & $(4.25 ; 6.53)$ & $(3.35 ; 5.38)$ & $(4.05 ; 6.37)$ & $(5.59 ; 8.55)$ \\
\hline & \multirow{4}{*}{ Wales } & Over- & 15.23 & 17.36 & 16.01 & 20.75 & 20.35 \\
\hline & & weight & $(13.68 ; 16.79)$ & $(15.64 ; 19.08)$ & $(14.38 ; 17.63)$ & $(18.87 ; 22.62)$ & $(18.34 ; 22.35)$ \\
\hline & & & 4.14 & 5.16 & 6.79 & 8.65 & 9.27 \\
\hline & & UD & $(3.28 ; 5)$ & $(4.16 ; 6.17)$ & $(5.67 ; 7.9)$ & $(7.35 ; 9.95)$ & $(7.82 ; 10.71)$ \\
\hline & \multirow{4}{*}{$\begin{array}{l}\text { Norther } \\
\text { Ireland }\end{array}$} & Over- & 15.61 & 18.45 & 17 & 23.87 & 21.15 \\
\hline & & weight & $(13.65 ; 17.57)$ & $(16.33 ; 20.58)$ & $(14.97 ; 19.02)$ & $(21.5 ; 26.23)$ & $(18.67 ; 23.63)$ \\
\hline & & Obesity & 5.36 & 6.85 & 7.45 & 8.33 & 8.25 \\
\hline & & & $(4.14 ; 6.58)$ & $(5.47 ; 8.23)$ & $(6.04 ; 8.87)$ & $(6.8 ; 9.86)$ & $(6.58 ; 9.92)$ \\
\hline
\end{tabular}

Proportions are based on cross-sectional samples and weighted with cross-sectional weights.

\section{Predictors of overweight and obesity at age 14}

Table 2 presents descriptive statistics of overweight and obesity at age 14, by categories of predictive factors. The most striking differences are by ethnicity and maternal 
education. For instance, $40 \%$ of Black children are classified as having excess weight at age 14 , compared to $26.2 \%$ of White children. Around $32 \%$ of children of mothers with GCSE or lower qualifications are classified as having excess weight, compared to $18 \%$ of children of mothers with a degree or higher qualification. Differences between active and inactive children are also noteworthy: the prevalence of excess weight is $21 \%$ among children exercising five days a week or more, compared to $33 \%$ among those exercising one or two days a week. Finally, the prevalence of excess weight among children who were breastfed for at least 3 months is significantly lower than among those who were not, at $21 \%$ and $29 \%$ respectively.

Table 2. Excess weight, and overweight and obesity at age 14: descriptive statistics

\begin{tabular}{|c|c|c|c|c|c|c|c|c|}
\hline & Factors & $\mathbf{N}^{\mathbf{a}}$ & $\begin{array}{c}\% \\
\text { excess } \\
\text { weight }\end{array}$ & $\begin{array}{c}p- \\
\text { value }\end{array}$ & $\begin{array}{l}\% \text { over } \\
\text { weight }\end{array}$ & $\begin{array}{c}p- \\
\text { value }\end{array}$ & $\begin{array}{c}\% \\
\text { obes } \\
\mathrm{e} \\
\end{array}$ & $\begin{array}{c}p- \\
\text { value }\end{array}$ \\
\hline \multirow{2}{*}{ Sex ${ }^{b}$} & Female & 5,326 & 28.6 & \multirow{2}{*}{0.002} & 20.4 & \multirow{2}{*}{0.001} & 8.2 & \multirow{2}{*}{0.801} \\
\hline & Male & 5,499 & 25.9 & & 18 & & 7.8 & \\
\hline \multirow{6}{*}{ Ethnicity } & White & 8,491 & 26.4 & \multirow{6}{*}{$<0.001$} & 18.9 & \multirow{6}{*}{$<0.001$} & 7.5 & \multirow{6}{*}{$<0.001$} \\
\hline & Mixed & 504 & 24.20 & & 15.1 & & 9.1 & \\
\hline & Indian & 290 & 26.40 & & 20.8 & & 5.6 & \\
\hline & Pakistani, Bangladeshi & 781 & 33.60 & & 20.9 & & 12.7 & \\
\hline & Black or Black British & 338 & 38.40 & & 29.6 & & 8.8 & \\
\hline & Other Ethnic group & 267 & 30.00 & & 19 & & 10.9 & \\
\hline \multirow{4}{*}{ Country ${ }^{b}$} & England & 7,122 & 27.0 & \multirow{4}{*}{0.006} & 19.0 & \multirow{4}{*}{0.072} & 7.9 & \multirow{4}{*}{0.186} \\
\hline & Wales & 1,500 & 29.8 & & 20.4 & & 9.4 & \\
\hline & Scotland & 1,158 & 26.3 & & 18.6 & & 7.6 & \\
\hline & Northern Ireland & 1,045 & 29.6 & & 21.2 & & 8.4 & \\
\hline \multirow{5}{*}{$\begin{array}{l}\text { Mother's } \\
\text { education }\end{array}$} & No academic/Other a & 1,549 & 31.7 & \multirow{5}{*}{$<0.001$} & 21.0 & \multirow{5}{*}{$<0.001$} & 10.8 & \multirow{5}{*}{$<0.001$} \\
\hline & GCSE D-G w/ voc>=L3 & 1,142 & 32.5 & & 21.5 & & 11.0 & \\
\hline & GCSE A-C \& A lev w/ & 3,821 & 27.2 & & 19.3 & & 8.0 & \\
\hline & A lev + voc $>=L 3 \&$ & 1,290 & 22.7 & & 17.4 & & 5.4 & \\
\hline & Degree or higher de & 2,024 & 18.2 & & 15.1 & & 3.1 & \\
\hline \multirow{2}{*}{$\begin{array}{l}\text { Exclusive } \\
\text { breastfeedin } \\
\mathrm{g} \text { for } 90 \text { days }\end{array}$} & No & 8,100 & 28.8 & \multirow[t]{2}{*}{$<0.001$} & 20.0 & \multirow[t]{2}{*}{$<0.001$} & 8.9 & \multirow[t]{2}{*}{$<0.001$} \\
\hline & Yes & 2,718 & 21.1 & & 16.2 & & 4.9 & \\
\hline \multirow{4}{*}{$\begin{array}{l}\text { Moderate/vi } \\
\text { gorous } \\
\text { physical } \\
\text { activity }\end{array}$} & $5+$ days a week & 4,110 & 21.1 & \multirow{4}{*}{$<0.001$} & 15.8 & \multirow{4}{*}{$<0.001$} & 5.2 & \multirow{4}{*}{$<0.001$} \\
\hline & 3-4 days a week & 3,632 & 29.2 & & 20.4 & & 8.9 & \\
\hline & 1-2 days a week & 2,562 & 33.4 & & 22.8 & & 10.7 & \\
\hline & Not at all & 454 & 28.4 & & 19.8 & & 8.6 & \\
\hline
\end{tabular}


Proportions measured using cross-sectional weights at sweep 6

a $\mathrm{N}$ is based on respondents having complete records on $\mathrm{BMI}$ and specific predictive factor, as a consequence not all groups sum up to 10,825 .

${ }^{\mathrm{b}}$ Prevalence differs slightly from those illustrated in Table 1 due to different sample selection

Table 3 presents the coefficients and standard errors from logistic models. Predictors of excess weight at age 14 include those described in section 2.3. In line with the unadjusted statistics in Table 2, children from Pakistani and Bangladeshi and Black ethnic backgrounds have a higher probability of having excess weight compared to White children. Having a mother with a degree or higher qualification, compared to one without a formal qualification, is associated with a reduced odds of excess weight of almost $30 \%(\mathrm{OR}=0.69,95 \% \mathrm{Cl}=0.55-0.87)$, while no significant differences are observed between intermediate levels of maternal education and no maternal qualification. Birth weight is positively associated with the probability of excess weight at age 14 , with the odds for excess weight 33\% higher per birthweight unit increase (100 grams). Children of mothers who smoked during pregnancy present higher odds of excess weight, as do those who were breastfed for less than 90 days. The indicator of puberty at age 14 shows that females and males who have started puberty have higher odds of excess weight but not obesity. Looking at behaviours, children who have ever smoked present higher odds of excess weight; children exercising 5 days a week or more are less likely to have excess weight. The indicator of a healthy diet is significantly associated with the odds of excess weight, but the odds ratio is very close to 1 indicating that a unit increase in the $\mathrm{ECl}$ scale impacts very modestly the risk of excess weight. Finally, sleeping behaviour is associated with excess weight (significance 10\%), with children going to sleep after midnight having a higher odds of excess weight.

Predictors of obesity are similar to those described above, and the magnitudes of the associations are in most cases larger. For instance, ethnic differences are starker in case of Pakistani and Bangladeshi children, while no difference is observed between White and Black children. Maternal education, house ownership, maternal smoking behaviour during pregnancy, breastfeeding and birthweight, are all predictive factors of obesity, and of a larger magnitude than observed for excess weight. On the other hand no difference in the odds of being obese was found between children with different sleeping and smoking habits. 
Table 3. Logit models, dependent variables: excess weight at age 14, and obesity at age 14

\begin{tabular}{|c|c|c|c|c|}
\hline \multirow{3}{*}{ Predictive factors } & \multicolumn{2}{|c|}{ Excess weight } & \multicolumn{2}{|c|}{ Obesity } \\
\hline & OR & S.E. & OR & S.E. \\
\hline & (1) & (2) & (3) & (4) \\
\hline Sex (ref. Female) & 0.958 & $(0.063)$ & 0.954 & $(0.100)$ \\
\hline Puberty started (ref. No) & $1.294^{* * *}$ & $(0.114)$ & 0.86 & $(0.137)$ \\
\hline Mixed & 0.909 & $(0.121)$ & 1.246 & $(0.276)$ \\
\hline Indian & 1.238 & $(0.265)$ & 0.987 & $(0.346)$ \\
\hline Pakistani, Bangladeshi & $1.892^{* * *}$ & $(0.203)$ & $2.476 * * *$ & $(0.474)$ \\
\hline Black or Black British & $2.061^{* * *}$ & $(0.329)$ & 1.294 & $(0.313)$ \\
\hline Other ethnic group & 1.319 & $(0.281)$ & 1.68 & $(0.569)$ \\
\hline GCSE D-G w/voc>=L3+ GCSE D-C or less & 1.101 & $(0.124)$ & 1.125 & $(0.189)$ \\
\hline GCSE A-C \& A lev $w /$ voc $>=L 3$ & 0.963 & $(0.082)$ & 0.896 & $(0.123)$ \\
\hline A lev + voc $>=$ L3 \& diplomas in $\mathrm{HE}$ & 0.843 & $(0.092)$ & $0.702 *$ & $(0.140)$ \\
\hline degree or higher degree & $0.695^{* * *}$ & $(0.075)$ & $0.453 * * *$ & $(0.108)$ \\
\hline Country (ref & $1.171^{*}$ & $(0.097)$ & 1.24 & $(0.164)$ \\
\hline England) & 1.006 & $(0.094)$ & 1.021 & $(0.173)$ \\
\hline Northern Ireland & $1.277^{* *}$ & $(0.128)$ & 1.185 & $(0.213)$ \\
\hline Number of siblings & $0.891^{* * *}$ & $(0.027)$ & $0.856 * * *$ & $(0.041)$ \\
\hline Single parent household & 0.924 & $(0.063)$ & 0.95 & $(0.105)$ \\
\hline Own house & $0.666^{* * *}$ & $(0.045)$ & $0.547 * * *$ & $(0.064)$ \\
\hline Mother smoked during pregnancy & $1.240 * * *$ & $(0.091)$ & $1.247^{*}$ & $(0.152)$ \\
\hline Breastfed $90+$ days & $0.794 * * *$ & $(0.056)$ & $0.713 * *$ & $(0.105)$ \\
\hline Birth weight & $1.337^{* * *}$ & $(0.069)$ & $1.467 * * *$ & $(0.146)$ \\
\hline $\mathrm{ECl}$ & $1.054^{* * *}$ & $(0.014)$ & $1.049 * *$ & $(0.023)$ \\
\hline Ever drunk heavily & 0.964 & $(0.096)$ & 0.911 & $(0.171)$ \\
\hline Ever smoked & $1.265^{* * *}$ & $(0.114)$ & 1.08 & $(0.178)$ \\
\hline 3-4 days a week & $1.589 * * *$ & $(0.104)$ & $1.809 * * *$ & (0.219) \\
\hline 1-2 days a week & $1.872^{* * *}$ & $(0.138)$ & $2.120 * * *$ & $(0.268)$ \\
\hline Not at all & $1.316^{* *}$ & $(0.180)$ & $1.475^{*}$ & $(0.340)$ \\
\hline Hours & 1.218 & $(0.350)$ & 1.621 & $(0.738)$ \\
\hline $\begin{array}{l}\text { watched TV } \\
\text { per day (ref. }\end{array}$ & 1.057 & $(0.291)$ & 1.516 & $(0.624)$ \\
\hline never) & 1.319 & $(0.369)$ & $2.019 *$ & $(0.841)$ \\
\hline $9-9: 59 p m$ & 0.95 & $(0.135)$ & 0.85 & $(0.181)$ \\
\hline $10-10: 59 \mathrm{pm}$ & 0.932 & $(0.130)$ & 1.004 & $(0.216)$ \\
\hline 11 -midnight & 1.146 & (0.169) & 1.177 & $(0.248)$ \\
\hline after midnight & $1.400^{*}$ & $(0.268)$ & 1.391 & $(0.362)$ \\
\hline Observations & 10,825 & & 10,818 & \\
\hline
\end{tabular}

*** $p<0.01,{ }^{* *} p<0.05, * p<0.1$

$\mathrm{OR}=$ odds ratio; $\mathrm{Voc}=$ vocational; $\mathrm{ECl}=$ Eating Choices Index; hrs=hours 
We also estimate a multinomial logit model to understand the factors associated with overweight and obesity separately, relative to normal weight. Relative risk ratios are presented in Table A2 in the Supporting Information. Results are very consistent with those in Table 3, suggesting that excess weight, which combines overweight and obesity, does not mask different directions or magnitude of effects between overweight and obesity. The most relevant finding is that in this model, not exercising at all compared to exercising $5+$ days per week increases the odds of both overweight and obesity, although significance levels are low (10\% and 5\% respectively).

\section{Transitions between ages 11 and 14}

Table 4 shows matrices of transitions between normal weight and excess weight between ages 11 and 14 (light grey area) and between obesity and non-obesity (dark grey area), separately by sex. Of males classified as normal weight at age $11,91 \%$ remain so at age 14 , and $19 \%$ have excess weight. Of males having excess weight at age $11,76 \%$ remain so at age 14 , and $24 \%$ become normal weight. For females, of those classified as normal weight at age $11,90 \%$ remain so at age 14 , and $10 \%$ switch to excess weight status; and amongst females classified as having excess weight at age 11, $74 \%$ remain so at age 14 , and $26 \%$ become normal weight. Therefore, transitions are very similar across sexes, if slightly more positive for males than for females. Transitions from obesity to non-obesity (i.e. normal weight and overweight) between ages 11 and 14 , separately by sex, are presented in the lower part of the table, and are also slightly more positive for males than females, especially in terms of transition out of obesity, with $34 \%$ of males and $27 \%$ of females classified as obese at age 11 transiting out to non-obese status at age 14 .

Table 4. Transition between excess weight (obesity) and normal weight (non-obesity) from age 11 to age 14, by sex

\begin{tabular}{|c|c|c|c|c|c|c|c|c|c|c|}
\hline & & & \multicolumn{4}{|c|}{ Males } & \multicolumn{4}{|c|}{ Females } \\
\hline & & & $\begin{array}{c}\text { Normal } \\
\text { weight }\end{array}$ & $\begin{array}{l}\text { Excess } \\
\text { weight }\end{array}$ & $\begin{array}{l}\text { Non- } \\
\text { obese }\end{array}$ & Obese & $\begin{array}{c}\text { Normal } \\
\text { weight }\end{array}$ & $\begin{array}{l}\text { Excess } \\
\text { weight }\end{array}$ & $\begin{array}{l}\text { Non- } \\
\text { obese }\end{array}$ & Obese \\
\hline$\stackrel{00}{4}$ & $\begin{array}{l}\text { Normal } \\
\text { weight }\end{array}$ & $\begin{array}{c}\text { row \% } \\
\mathrm{N}\end{array}$ & $\begin{array}{c}91.3 \\
(3,549)\end{array}$ & $\begin{array}{c}8.7 \\
(309)\end{array}$ & & & $\begin{array}{c}89.7 \\
(3,273)\end{array}$ & $\begin{array}{c}10.3 \\
(356)\end{array}$ & & \\
\hline
\end{tabular}




\begin{tabular}{|c|c|c|c|c|c|c|c|c|c|}
\hline $\begin{array}{l}\text { Excess } \\
\text { weight }\end{array}$ & $\begin{array}{c}\text { row } \% \\
\mathrm{~N}\end{array}$ & $\begin{array}{c}24.4 \\
(313)\end{array}$ & $\begin{array}{c}75.6 \\
(948)\end{array}$ & & & $\begin{array}{c}26.3 \\
(355)\end{array}$ & $\begin{array}{c}73.7 \\
(1,020)\end{array}$ & & \\
\hline $\begin{array}{l}\text { Non- } \\
\text { obese }\end{array}$ & $\begin{array}{c}\text { row } \% \\
\mathrm{~N}\end{array}$ & & & $\begin{array}{c}96.8 \\
(4,637)\end{array}$ & $\begin{array}{c}3.2 \\
(146)\end{array}$ & & & $\begin{array}{c}96.1 \\
(4,537)\end{array}$ & $\begin{array}{c}3.9 \\
(167) \\
\end{array}$ \\
\hline Obese & $\begin{array}{c}\text { row } \% \\
\mathrm{~N}\end{array}$ & & & $\begin{array}{l}33.8 \\
(94)\end{array}$ & $\begin{array}{c}66.2 \\
(206)\end{array}$ & & & $\begin{array}{l}27.4 \\
(96)\end{array}$ & $\begin{array}{l}72.6 \\
(204)\end{array}$ \\
\hline
\end{tabular}

Percentages are row percentages and measured using longitudinal weights at sweep $6 . \mathrm{N}=$ subsample size is not weighted.

\section{Modelling transitions}

We next estimate a model to understand the factors associated with the likelihood of transiting out of excess weight between ages 11 and 14. Results are shown in Table 4. The most striking result is the association between reaching puberty and both overweight and obesity: respondents of excess weight status at age 11 had an almost $50 \%$ higher likelihood of switching to normal weight at 14 if they had reached puberty by then; for transition out of obesity the correlation is even larger, with respondents who had reached puberty three times more likely to become non-obese at age 14, compared to those who had not reached puberty. The other factors associate with transitions to normal weight from age 11 to 14 include: high level of maternal education, associated with an increased likelihood of transiting out of excess weight (significant at the $10 \%$ level), home ownership, birthweight, with higher birthweight associated with lower odds of transiting out excess weight at age 14. Some healthrelated behaviours of respondents show a strong association with the probability of transiting from excess to normal weight between 11 and 14: respondents who have never smoked and those doing vigorous physical activity $5+$ days a week present higher chances of transiting out excess weight at age 14. For transition out of obesity between 11 and 14, almost no factor is significant. Physical activity is the exception, with frequent exercise being a protective factor. The lack of significance is likely related to low power, with 600 respondents obese at age 11 .

Table 5. Logit models: ORs of transiting out of excess weight and obesity at age 14, from age 11 


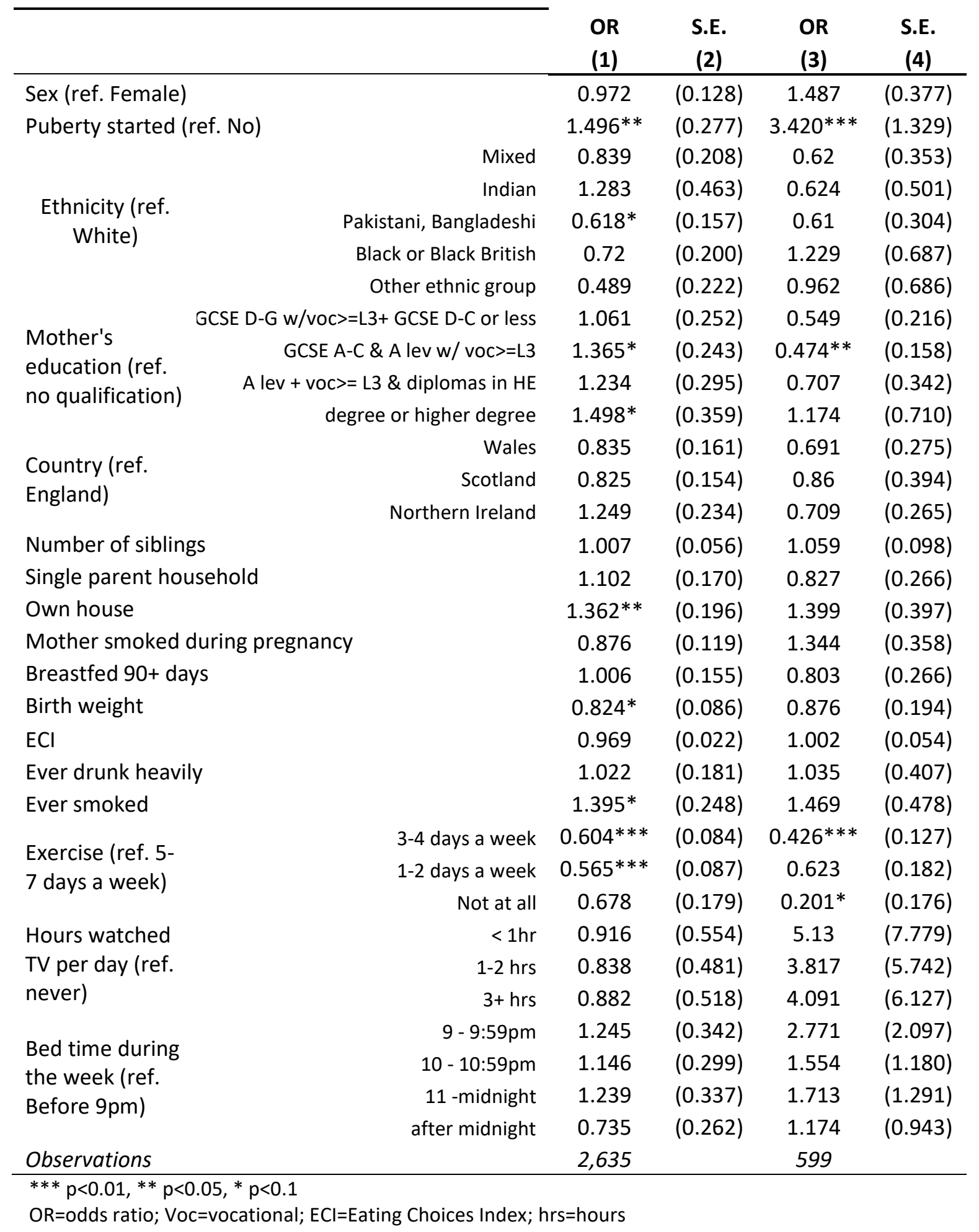

\section{Discussion}

This study uses unique data from the UK Millennium Cohort Study and presents new evidence on levels of, and trends in, overweight and obesity amongst a nationally 
representative and contemporaneous sample of adolescents in the UK today. It shows that around $8 \%$ of 14 -year olds are classified as obese and $20 \%$ overweight, with proportions similar across males and females. The study finds that the stark increases in excess weight previously observed between ages 7 and 11 , from $20 \%$ to $28 \%$ (Platt et al., 2014) $)^{1}$, have stabilized at $27 \%$ by age 14 , by which point no sustained increases in overweight or obesity are observed. Whilst other recent research provide evidence of a secular plateauing (Collaboration NCDRF, 2017; Health Survey for England, 2013) of the increasing trends in childhood overweight and obesity in the most recent generations of children, our study provides important new evidence that increasing trends in excess weight have stabilized, based on life-course analysis of a cohort born around the Millennium. Whether this plateauing persists as the cohort continues to age remains to be seen and future MCS sweeps will allow for monitoring of this phenomenon. It remains unknown to what extent future young generations will be affected by the obesity epidemic. What is reasonable to expect is that the prevalence of overweight and obese children and adolescents will be affected by, and indeed reinforces, the Government commitment to reducing obesity in childhood. Hence, a continuous monitoring of trends will be essential and needed in the upcoming years. Moreover, experience learnt from today's young generations is an important instrument to take on this challenge.

For this reason, the second objective of this work was to identify factors associated with risk of overweight and obesity at age 14 . The intention was to identify high-risk profiles to inform policy making and help shape and target interventions appropriately. For example, we find that ethnic differences in BMI are stark, with children from Indian, Pakistani and Bangladeshi and Black ethnic backgrounds displaying a higher probability of excess weight status than White children. An important consideration when considering ethnic inequality, however, is that ethnic differences in body composition can be very important when developing BMI cut-points, especially for Asian children (Liu et al., 2011). We do not consider ethnic-specific BMI cut-points in order to be consistent with previous studies and aid comparability, but acknowledge this potential limitation.

\footnotetext{
${ }^{1}$ Platt et al. used UK 1990 thresholds to classify overweight and obesity, hence their estimates are different, but direction of trends is the same.THIS IS IMPORTANT INFORMATION - PERHAPS PUT IN THE TEXT
} 
We also identify background characteristics that are associated with reduced risk of excess weight: high maternal education, breastfeeding, and home ownership; and risk factors associated with raised risk of excess weight, including maternal smoking during pregnancy, for which our findings are in line with recent and less recent studies that found that intrauterine exposure to inhaled smoke products rather than lifestyle factors associated with maternal smoking accounts for the association between overweight/obesity and maternal smoking during pregnancy (Harris, Willett, \& Michels, 2013; L. Li et al., 2016; Toschke et al., 2002; Von Kries et al., 2002). It is important to distinguish between factors relating to early life and characteristics in adolescence, to aid in targeting both the optimal time and way to intervene. In the case of the MCS cohort, specifically, knowing how respondents' behaviours are associated with the risk of overweight or obesity would permit the design and implementation of targeted interventions to impact the cohort members' lives. We find that the most important individual protective behavioural factor is frequent exercise. Current national physical activity guidelines for children aged 5 to 18 recommend that children and young people engage in moderate to vigorous intensity physical activity for at least 60 minutes every day (Department of Health, 2011). Our results support the guidelines that exercise should be done every day, as we find that even those who exercise 3-4 days a week have higher risk of excess weight compared to those who exercise 5 days a week or more. Also, smoking and poor sleeping behaviours show some association with overweight, but not with obesity. The composite indicator of a healthy diet does not appear protective against excess weight, contrary to what we had expected. Therefore, we rerun the multivariate model presented in Table 3 including the items composing the index separately and all together (results are available upon request), but results do not change, with the exception of breakfast which correlates as expected: those having breakfast every day have lower odds of overweight and obesity. Further research is needed to understand the role of diet in terms of both calorie intake and healthy eating habits.

Another contribution of this work is to study transitions into and out of overweight/obese statuses, from early adolescence to mid-adolescence, a critical stage coinciding with the transition from primary to secondary school, increased 
independence, and important physiological change. For the large part, we observe considerable persistence in weight status from 11 to 14 , in agreement with results of the study of Geserick et al. just published on the New England Journal of Medicine (Geserick et al., 2018). Where transitions occur, the direction tends to be positive, with a higher probability of transiting out of excess weight/obesity than into it. This important finding is suggestive of a positive trend in adolescents' development. However, it must be regarded alongside some limitations. First, the change in BMI resulting in a change in status could be very small and may largely reflect those on the border of excess weight. Second, we considered two age points in adolescence development, 11 and 14, and were unable to capture fluctuations between these ages. Finally, restricting the analysis to those having excess weight at age 11 results in a large reduction in sample size and statistical power, particularly in the case of transitions out of obesity. Nevertheless, some striking results have emerged, particularly regarding puberty. Amongst those of excess weight at age 11, females who have had their menarche and males who have experienced voice deepening have higher odds of transiting to normal weight compared to those who have not had these pubertal changes. The literature has mostly explored the association between obesity/ overweight and puberty in terms of the former determining the latter, and obesity has been found to contribute to early onset of puberty in females, while in males there is insufficient data (Li et al., 2017). The direction of the association we find may appear counterintuitive. However, it is important to bear in mind that we are considering only a select sample of children who were overweight or obese at age 11. Among this subsample the proportion of children that had reached puberty by age 11 was larger than among their normal weight peers, and it may be that in this case having reached puberty is associated with transitions as a protective factor.

We believe these findings can have important implications, particularly relevant in terms of policy targeted at adolescents and young adults as well as children approaching adolescence. Results are supported by some unique strengths of this study, that must however be considered alongside limitations. We use a very rich longitudinal cohort study representative of contemporary adolescents, and this allows us to know in depth many spheres of their lives. At least two limitations arise when we study changes across adolescence, such as overweight and obesity transitions, that are influenced by 
both genetic and non-genetic factors. The first is that in this study we can explore only non-genetic factors such as socio-economic environment; the second is that the time intervals across surveys do not allow us to monitor and capture intermediate changes and we may be able to capture only the results of processes that have taken place between age 11 and 14. Moreover, no causal effects can be claimed from results of analyses. We identify risk factors for overweight and obesity, but cannot claim that their association with the risk of overweight/obesity is causal, nor the underlying mechanisms through which they act, or the direction of association, as was briefly discussed in regards to puberty. Nevertheless, the identification of predictors of overweight and obesity is an important first step to monitor subjects at risk and to collect appropriate information on the possible mechanisms through which they may affect BMI. 


\section{What is already known on this subject}

- Childhood obesity and overweight epidemic is growing globally

- Children who are overweight or obese face an increased risk of many health problems

- Overweight and obesity rates in childhood increase as children grow up

\section{What this study adds}

- Proportion of excess weight have stabilized from age 11 to age 14 , though at an alarmingly high level

- Boys are slightly more likely than girls to become normal weight at age 14 having been overweight or obese at 11.

- Predictors of transiting out of excess weight and obesity include child's active behaviour and puberty onset.

\section{CONFLICT OF INTEREST}

The authors declare no conflict of interest.

\section{ACKNOWLEDGEMENTS}

We are grateful to the Centre for Longitudinal Studies, UCL Institute of Education, for the use of these data and to the UK Data Archive and UK Data Service for making them available. However, they bear no responsibility for the analysis or interpretation of these data. We acknowledge funding from the ESRC (grant number ES/K005987/1) and a consortium of government departments : Department for Education, Department of Health, Ministry of Justice, Home Office, Department for Transport, Department of Work and Pensions, Welsh Government and Department for Employment and Learning (Northern Ireland). We thank Dr David Bann for valuable comments. All errors are the responsibility of the authors. This work is based on original research, has not been previously published and has not been submitted for publication elsewhere.

\section{List of figures and Tables}

Figure 1. Overweight and obesity, by age and sex

Figure 2. Overweight and obesity, by age and country ${ }^{a}$

a Proportions are based on cross-sectional samples and weighted with cross-sectional weights.

Table 1. Excess weight, and overweight and obesity at age 14: descriptive statistics Proportions measured using cross-sectional weights at sweep 6

a $\mathrm{N}$ based on respondents having complete records on all variables included in the model presented in table 3 .

${ }^{b}$ Prevalence differs slightly from those illustrated in Figures 1 and 2 due to different sample selection

Table 2. Linear probability models, dependent variables: excess weight at age 14 , and obesity at age 14

$* * * p<0.01, * * p<0.05, * p<0.1$

Table 3. Transition between excess weight (obesity) and normal weight (non-obesity) from age 11 to age 14 , by sex

Proportions measured using longitudinal weights at sweep 6. First figure in each cell is sample size; second figure is percentage.

Table 4. Probability of transiting out of excess weight and obesity at age 14, from age 11

a Measured at age 11 (sweep 5). 


\section{References}

Abarca-Gómez, Leandra, Abdeen, Ziad A., Hamid, Zargar Abdul, Abu-Rmeileh, Niveen M., Acosta-Cazares, Benjamin, Acuin, Cecilia, . . Ezzati, Majid. (2017). Worldwide trends in body-mass index, underweight, overweight, and obesity from 1975 to 2016: a pooled analysis of 2416 population-based measurement studies in 128.9 million children, adolescents, and adults. The Lancet, 390(10113), 2627-2642. doi: https://doi.org/10.1016/S0140-6736(17)32129-3

Al-Awadhi, Nora, Al-Kandari, Nouf, Al-Hasan, Teebah, AlMurjan, Daliah, Ali, Salhah, \& Al-Taiar, Abdullah. (2013). Age at menarche and its relationship to body mass index among adolescent girls in Kuwait. BMC Public Health, 13, 29-29. doi: 10.1186/1471-2458-13-29

Apfelbacher, Christian J, Loerbroks, Adrian, Cairns, John, Behrendt, Heidrun, Ring, Johannes, \& Krämer, Ursula. (2008). Predictors of overweight and obesity in five to seven-year-old children in Germany: results from cross-sectional studies. BMC Public Health, 8(1), 171.

Asia Pacific Cohort Studies Collaboration. (2004). Body mass index and cardiovascular disease in the Asia-Pacific Region: an overview of 33 cohorts involving 310000 participants. International journal of epidemiology, 33(4), 751-758. doi: https://doi.org/10.1093/ije/dyh163

Bralic, I., Tahirovic, H., Matanic, D., Vrdoljak, O., Stojanovic-Spehar, S., Kovacic, V., \& BlazekovicMilakovic, S. (2012). Association of early menarche age and overweight/obesity. J Pediatr Endocrinol Metab, 25(1-2), 57-62. doi: 10.1515/jpem-2011-0277

Bridger, T. (2009). Childhood obesity and cardiovascular disease. Paediatr Child Health, 14(3), 177-182. doi: 10.1186/s12889-017-4691-z

Chinn, Susan, \& Rona, Roberto J. (2001). Prevalence and trends in overweight and obesity in three cross sectional studies of British children, 1974-94. BMJ : British Medical Journal, 322(7277), 24-26. doi: https://doi.org/10.1136/bmj.322.7277.24

Cole, Tim J., Flegal, Katherine M., Nicholls, Dasha, \& Jackson, Alan A. (2007). Body mass index cut offs to define thinness in children and adolescents: international survey. $B M J$ : British Medical Journal, 335(7612), 194-194. doi: 10.1136/bmj.39238.399444.55

Collaboration NCDRF. (2017). Worldwide trends in body-mass index, underweight, overweight, and obesity from 1975 to 2016: a pooled analysis of 2416 population-based measurement studies in 128.9 million children, adolescents, and adults. Lancet. doi: 10.1016/s0140-6736(17)32129-3

Connelly, Roxanne, \& Platt, Lucinda. (2014). Cohort Profile: UK Millennium Cohort Study (MCS). International Journal of Epidemiology, 43(6), 1719-1725. doi: 10.1093/ije/dyu001

Conolly, Anne, \& Neave, Alison. (2016). Health Survey for England 2015 Children's body mass index, overweight and obesity.

Department of Health, Physical Activity, Health Improvement and Protection. (2011). Start Active, Stay Active: A report on physical activity for health from the four home countries' Chief Medical Officers. The Department of Health.

Emerging Risk Factors Collaboration. (2011). Separate and combined associations of body-mass index and abdominal adiposity with cardiovascular disease: collaborative analysis of 58 prospective studies. The Lancet, 377(9771), 1085-1095. doi: https://doi.org/10.1016/S0140-6736(11)60105-0

Fitzsimons, Emla. (2017). Millennium Cohort Study, Sixth Survey 2015-2016 User Guide (First Edition ed.): UCL Institute of Education, Centre for Longitudinal Studies.

Geserick, M, Vogel, M, Gausche, R, Lipek, T, Spielau, U, Keller, E, ... Körner, A. (2018). Acceleration of BMI in Early Childhood and Risk of Sustained Obesity. New England Journal of Medicine, 379(14), 1303-1312.

Gillman, Matthew W, Rifas-Shiman, Sheryl L, Camargo Jr, Carlos A, Berkey, Catherine S, Frazier, A Lindsay, Rockett, Helaine RH, . . . Colditz, Graham A. (2001). Risk of overweight among adolescents who were breastfed as infants. Jama, 285(19), 2461-2467. 
Güngör, Neslihan Koyuncuoğlu. (2014). Overweight and obesity in children and adolescents. Journal of clinical research in pediatric endocrinology, 6(3), 129.

Guo, S. S., Wu, W., Chumlea, W. C., \& Roche, A. F. (2002). Predicting overweight and obesity in adulthood from body mass index values in childhood and adolescence. Am J Clin Nutr, 76(3), 653-658. doi: 10.1093/ajcn/76.3.653

Han, Joan C., Lawlor, Debbie A., \& Kimm, Sue Y. S. (2010). Childhood Obesity - 2010: Progress and Challenges. Lancet, 375(9727), 1737-1748. doi: 10.1016/S0140-6736(10)60171-7

Harris, Holly R., Willett, Walter C., \& Michels, Karin B. (2013). Parental smoking during pregnancy and risk of overweight and obesity in the daughter. International journal of obesity (2005), 37(10), 1356-1363. doi: 10.1038/ijo.2013.101

Health Survey for England. (2013). 2012 -Trend tables. (database on the Internet). Retrieved 21 November 2017, from http://www.hscic.gov.uk/catalogue/PUB13219

Hediger, Mary L, Overpeck, Mary D, Kuczmarski, Robert J, \& Ruan, W June. (2001). Association between infant breastfeeding and overweight in young children. Jama, 285(19), 24532460.

Inchley, Jo, Currie, Dorothy, Jewell, Jo, \& Breda, João. (2017). Adolescent obesity and related behaviours.

Johnson, William, Li, Leah, Kuh, Diana, \& Hardy, Rebecca. (2015). How has the age-related process of overweight or obesity development changed over time? Co-ordinated analyses of individual participant data from five United Kingdom birth cohorts. PLOS medicine, 12(5), e1001828. doi: https://doi.org/10.1371/journal.pmed.1001828

Joshi, H., \& Fitzsimons, E. (2016). The UK Millennium Cohort Study: the making of a multipurpose resource for social science and policy in the UK. Longitudinal and Life Course Studies, 7(4), 409-430. doi: 10.14301/Ilcs.v7i4.416

Ketende, SC, \& Jones, EM. (2011). The millennium cohort study: User guide to analysing MCS data using STATA. London: Centre for Longitudinal Studies, Institute of Education.

Kramer, Michael S, Matush, Lidia, Bogdanovich, Natalia, Aboud, Frances, Mazer, Bruce, Fombonne, Eric, ... Igumnov, Sergei. (2009). Health and development outcomes in 6.5$y$-old children breastfed exclusively for 3 or 6 mo-. The American journal of clinical nutrition, 90(4), 1070-1074.

Lang, J. E. (2012). Obesity, Nutrition, and Asthma in Children. Pediatr Allergy Immunol Pulmonol, 25(2), 64-75. doi: 10.1089/ped.2011.0137

Li, Liu, Qin, Deng, Xu, Chen, Yiwen, \& Liu, Shudan. (2017). Association between obesity and puberty timing: a systematic review and meta-analysis. International journal of environmental research and public health, 14(10), 1266.

Li, L., Peters, H., Gama, A., Carvalhal, M. I., Nogueira, H. G., Rosado-Marques, V., \& Padez, C. (2016). Maternal smoking in pregnancy association with childhood adiposity and blood pressure. Pediatr Obes, 11(3), 202-209. doi: 10.1111/ijpo.12046

Liu, A., Byrne, N. M., Kagawa, M., Ma, G., Poh, B. K., Ismail, M. N., .. Hills, A. P. (2011). Ethnic differences in the relationship between body mass index and percentage body fat among Asian children from different backgrounds. Br J Nutr, 106(9), 1390-1397. doi: $10.1017 / \mathrm{s} 0007114511001681$

Lobstein, T. J., James, W. P., \& Cole, T. J. (2003). Increasing levels of excess weight among children in England. Int J Obes Relat Metab Disord, 27(9), 1136-1138. doi: 10.1038/sj.ijo.0802324

Massion, Samuel, Wickham, Sophie, Pearce, Anna, Barr, Ben, Law, Catherine, \& TaylorRobinson, David. (2016). Exploring the impact of early life factors on inequalities in risk of overweight in UK children: findings from the UK Millennium Cohort Study. Archives of Disease in Childhood, 101(8), 724-730. doi: 10.1136/archdischild-2015-309465 
Mostafa, Tarek, \& Ploubidis, George. (2017). Millennium Cohort Study, Sixth Survey 2015-2016, Technical report on response (Age 14): UCL Institute of Education, Centre for Longitudinal Studies.

Ng, M., Fleming, T., Robinson, M., Thomson, B., Graetz, N., Margono, C., . . Gakidou, E. (2014). Global, regional, and national prevalence of overweight and obesity in children and adults during 1980-2013: a systematic analysis for the Global Burden of Disease Study 2013. Lancet, 384(9945), 766-781. doi: 10.1016/S0140-6736(14)60460-8

Platt, Lucinda, Smith, Kate, Parsons, Samantha, Connelly, Roxanne, Joshi, Heather, Rosenberg, Rachel, . . Chatzltheocharl, Stella. (2014). Millennium Cohort Study: initial findings from the age 11 survey: Centre for Longitudinal Studies, Institute of Education.

Pot, G. K., Richards, M., Prynne, C. J., \& Stephen, A. M. (2014). Development of the Eating Choices Index (ECI): a four-item index to measure healthiness of diet. Public Health Nutr, 17(12), 2660-2666. doi: 10.1017/S1368980013003352

Pulgaron, E. R., \& Delamater, A. M. (2014). Obesity and Type 2 Diabetes in Children: Epidemiology and Treatment. Curr Diab Rep, 14(8), 508. doi: 10.1007/s11892-014-0508$y$

Renehan, Andrew G, Tyson, Margaret, Egger, Matthias, Heller, Richard F, \& Zwahlen, Marcel. (2008). Body-mass index and incidence of cancer: a systematic review and meta-analysis of prospective observational studies. The Lancet, 371(9612), 569-578. doi: 10.1016/S0140-6736(08)60269-X

Russell-Mayhew, Shelly, McVey, Gail, Bardick, Angela, \& Ireland, Alana. (2012). Mental health, wellness, and childhood overweight/obesity. Journal of Obesity, 2012. doi: $10.1155 / 2012 / 281801$

Shrewsbury, Vanessa, \& Wardle, Jane. (2008). Socioeconomic status and adiposity in childhood: a systematic review of cross-sectional studies 1990-2005. Obesity, 16(2), 275-284.

Tanner, James Mourilyan. (1962). Growth at adolescence.

Thibault, Helene, Contrand, Benjamin, Saubusse, Elodie, Baine, Magali, \& Maurice-Tison, Sylvie. (2010). Risk factors for overweight and obesity in French adolescents: physical activity, sedentary behavior and parental characteristics. Nutrition, 26(2), 192-200.

Toschke, André, Koletzko, Berthold, Slikker, William, Hermann, Monika, \& von Kries, Rüdiger. (2002). Childhood obesity is associated with maternal smoking in pregnancy. European journal of pediatrics, 161(8), 445-448.

Vieno, Alessio, Santinello, Massimo, \& Martin, Maria Cristiana. (2005). Epidemiology of overweight and obesity among Italian early adolescents: relation with physical activity and sedentary behaviour. Epidemiology and Psychiatric Sciences, 14(2), 100-107.

Von Kries, Rüdiger, Toschke, André Michael, Koletzko, Berthold, \& Slikker Jr, William. (2002). Maternal smoking during pregnancy and childhood obesity. American journal of epidemiology, 156(10), 954-961.

Wang, Youfa, \& Lobstein, T. I. M. (2006). Worldwide trends in childhood overweight and obesity. International Journal of Pediatric Obesity, 1(1), 11-25. doi: 10.1080/17477160600586747

Widerøe, Marius, Vik, Torstein, Jacobsen, Geir, \& Bakketeig, Leiv S. (2003). Does maternal smoking during pregnancy cause childhood overweight? Paediatric and perinatal epidemiology, 17(2), 171-179.

Wilkie, Hannah J, Standage, Martyn, Gillison, Fiona B, Cumming, Sean P, \& Katzmarzyk, Peter T. (2016). Multiple lifestyle behaviours and overweight and obesity among children aged 9-11 years: results from the UK site of the International Study of Childhood Obesity, Lifestyle and the Environment. BMJ open, 6(2), e010677.

Wray-Lake, L., Crouter, A. C., \& McHale, S. M. (2010). Developmental Patterns in DecisionMaking Autonomy across Middle Childhood and Adolescence: European American Parents' Perspectives. Child Dev, 81(2), 636-651. doi: 10.1111/j.1467-8624.2009.01420.x 
